\title{
NUCLEAR SIZE IN THE NERVE CELLS OF THE BEE DURING THE LIFE CYCLE
}

\author{
W. M. SMALLWOOD AND RUTH L. PHILlIPS
}

(From the Zoological Laboratory of Syracuse University, C. W. Hargitt, Director.)

ONE FIGURE

The following study of nuclear size in the nerve cells of the antennal lobe of the bee was undertaken for the purpose of learning what are the normal conditions and what, if any, changes they undergo during the life cycle.

Bees afford exceptionally good material for such work because all members of a given swarm are of identical parentage; all spend an inactive larval existence, and the life cycle of individuals varies according to type and season. Drones live through the summer, queens may live for seven years, and the workers, with which we are concerned in this paper, have a life cycle varying from about six weeks in the summer to about six months for the insects hatched from an autumn brood.

Hodge $^{1}$ ('92) published his observations on daily fatigue in the bee, the sparrow and the cat. In this work he chose the cells of the antennal lobes because they are easily located. We have limited our study to the cells of this region for the same reason. It is usually considered that excessive stimuli in the form of an immense amount of normal daily work, electrical stimulation, or surgical shock result in a decrease of nuclear size among the nerve cells. That such assumptions are commonly held, the work of Crile ${ }^{2}$ and Hodge shows.

Conklin $^{3}$ ('12) has shown that there is a normal relation between the size of a cell and its nucleus, and Kocher ${ }^{4}$ ('16) has

\footnotetext{
1 Journal of Mornhology, vol, 7, 1892, p. 153.

2 Journal of the American Medical Association, vol. 57, no. 23, 1911, p. 1812.

${ }^{3}$ Journal of Experimental Zoölogy, vol. 12, 1912, p. 1.

4 Journal of Comparative Neurology, vol. 26, no. 3, 1916.
} 
questioned the results obtained by Hodge and Crile. Our work was begun in 1910-11, but the opportunity for completing it did not present itself until this summer. We have re-examined our earlier work and supplemented it with additional material collected and prepared in the same way as that obtained previously.

This material consists of the following stages covering the life cycle of the honey bee.

1. Recently hatched larvae.

2. Half-grown larvae.

3. Fully-grown larvae.

4. Early pupae.

5. Mid-pupae.

6. Late pupae.

7. Newly hatched adults.

8. Young adults taken at 6.30 a.m.

9. Young adults taken at $6.30 \mathrm{p} . \mathrm{m}$.

10. Old adults taken at 6.30 a.m.

11. Old adults taken at $6.30 \mathrm{p} . \mathrm{m}$.

12. Adults taken at close of the winter season.

Several different fixatives were tried, but the only ones found successful were osmic sublimate, 1 per cent osmic acid, 1 per cent glacial acetic, and sublimate to saturation, Carnoy's and Ohlmacher's fluids. Only one individual, that one of stage (8), included in our study was fixed with osmic sublimate.

No attempt was made to dissect out the brains of the larvae, which were embedded entire. The brains of pupae and adults were excised. Sections were cut from four to seven micra thick in paraffin of $54^{\circ}$, and stained in iron haematoxylin with Bordeaux red as a counter stain.

The Zeiss and Leitz eyepiece micrometers were used, readings being computed in micra. We tried to use the planimeter in our work this summer, but found it impracticable in measuring such small nuclei.

There are according to Kenyon, ${ }^{5}$ four general regions in the brain of the bee; the dorso-cerebron, the ventro-cerebron, and

. Journal of Comparative Neurology, vol. 6, 1896. 
the deuto-cerebron or antennal lobes. These latter arise from the ventro-anterior side of the dorso-cerebron by two stalks of fibrillar substance. Each stalk expands into a convoluted spherical mass of fibers from which the nerves of the antennae arise. This fibrillar core is surrounded by nerve cells. In the adult these cells are of three types as far as nuclear size is concerned, which conform to the types described by Kenyon. These are, multipolar giant cells, large and small ganglion cells. In the larva and pupa we find large neuroblasts which give rise to the cells of the last two types by mitosis and finally themselves transform into the giant cells of the adult.

It is manifestly impossible to measure all the nuclei in any ganglion in such a study as this. We must be content to choose and select with as much care as possible, such cells as appear to belong in the same general group and from a study of their measurements attempt to gain some insight into the problems which concern the whole mass of cells. Such cells in each class were chosen as appeared to be fair representatives of the respective groups. It is probable that others in going over the same material would select and measure other cells and so arrive at average measurements somewhat different from those given in our tables. Our experience leads us to believe, however, that the general form of the curves derived from a study of the data would not be materially altered.

Usually we have found no difficulty in making a decision as to the group in which any particular cell belongs. There have been a few instances, however, where the mere matter of size seemed to be insufficient to control the matter of classification. In such cases we have taken into consideration the general appearance of the cells, both as to nucleus and cytoplasm, before placing the cell in one or another group. In the case of the giant cells care was taken to choose those in which the plane of section passed approximately through the center of the nucleus.

Each nucleus was measured in its longest and shortest diameter and the average of these taken as the mean diameter. The results of these measurements are summed up in the following table which gives the average nuclear diameter for the three 


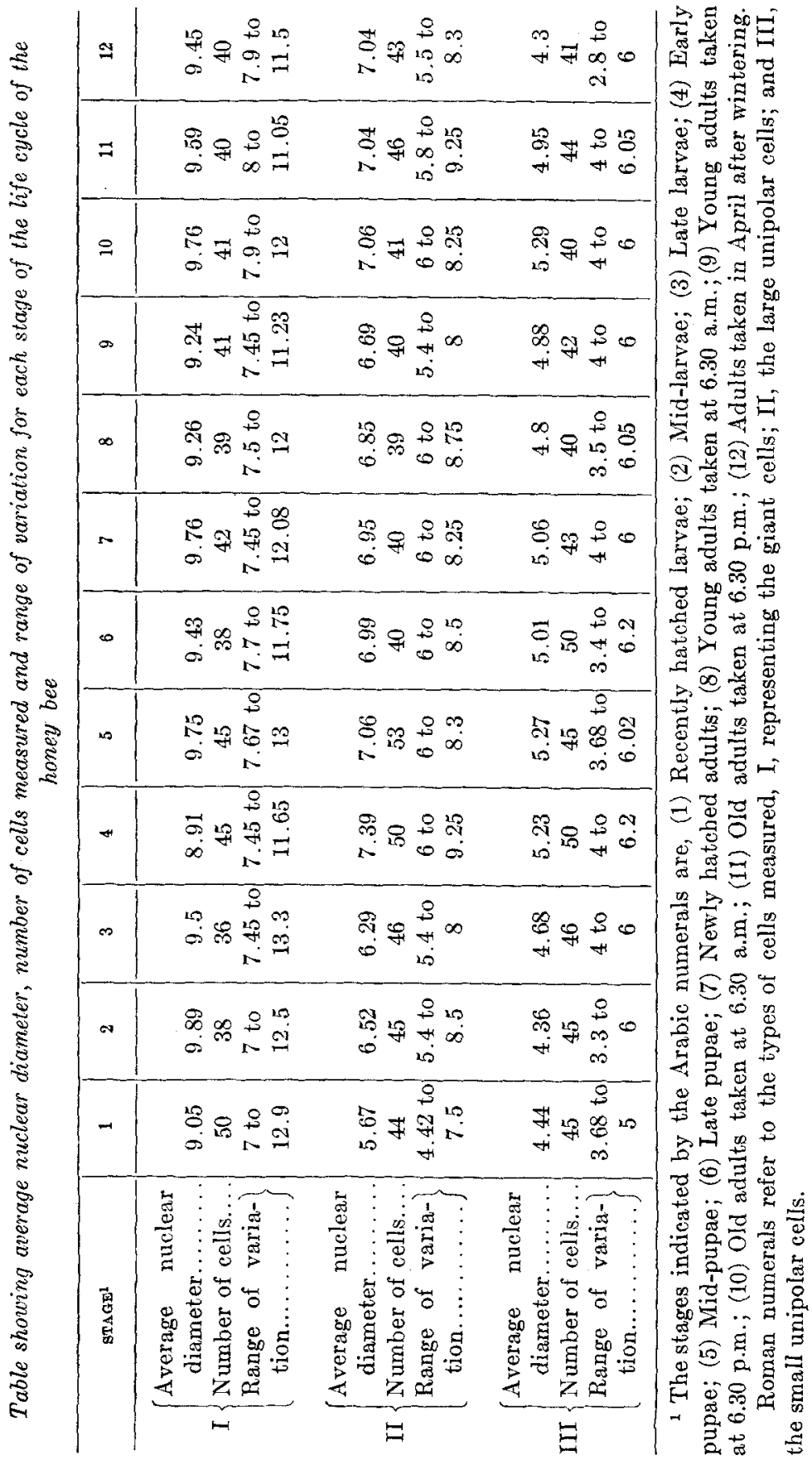


types of cells in each stage, the number of cells measured and the range of variation for each. The results are shown graphically in the curves which follow the table.

A study of these results together with the plotted curves indicates a number of fundamental conditions. In all of the stages in each of the three groups of cells measured, there is a wide range of variation in the size of the nucleus. This cannot be charged to the normal swelling of the nucleus just before mitosis, for the same variation is present in the cells of the bee that had lived through the winter and in the queens studied. That variation is an ever-present condition in all living things is a truism, but when we attempt to indicate which organ or tissue is responsible for the variation most of the observations have been simply a record of the organic fact of variation. This study claims that the cells and their parts such as the nuclei are the variable factors that are responsible for the variation in the tissue or organ. Any explanation of the cause of such variations has to recognize the part played by cells. It seems to the writers that this natural and normal variation plays an important part in explaining such conclusions as Crile comes to in regard to the effects of shock. Before we can accept his conclusions, we must determine what is the normal range of variation for the group of cells that he studied. It would have been a relatively easy problem to indicate a definite tendency beginning with young adults and passing to the winter bee by simply taking some of the large cells in the young adult with nuclear diameter of 12 micra and comparing them with those that measure 7.9 micra. This would give a definite shrinkage with age; but when the average of some forty cells is taken, the total is 9.26 micra for the young adult, and 9.45 for the winter bee. We interpret the difference to be due to the normal variation present in these cells and do not regard the larger average for the winter bee in nerve cells of type I as a measure of the extent of change that as come with fatigue or age.

The second inference to be drawn from these measurements is the independent sequence of growth changes in these three types of nerve cells. There is a more or less rhythmic variation 
in the series of measurements made when the plotted curves are viewed as a whole. Take the large multipolar cells which start in with an average diameter of 9.05 micra; then increase to 9.89 during the mid-larva period, to be followed by a marked decline to the mid-pupa period. This is followed by an increase which is almost the same as the newly hatched adult and the old adult taken at 6.30 a.m. The average nuclear diameter of the winter bee is larger than the recently hatched larvae, late larvae, early pupae and young adults taken early in the morning. A similar study of the variations in nerve cells of Type II indicates a different series of growth sequences. Here

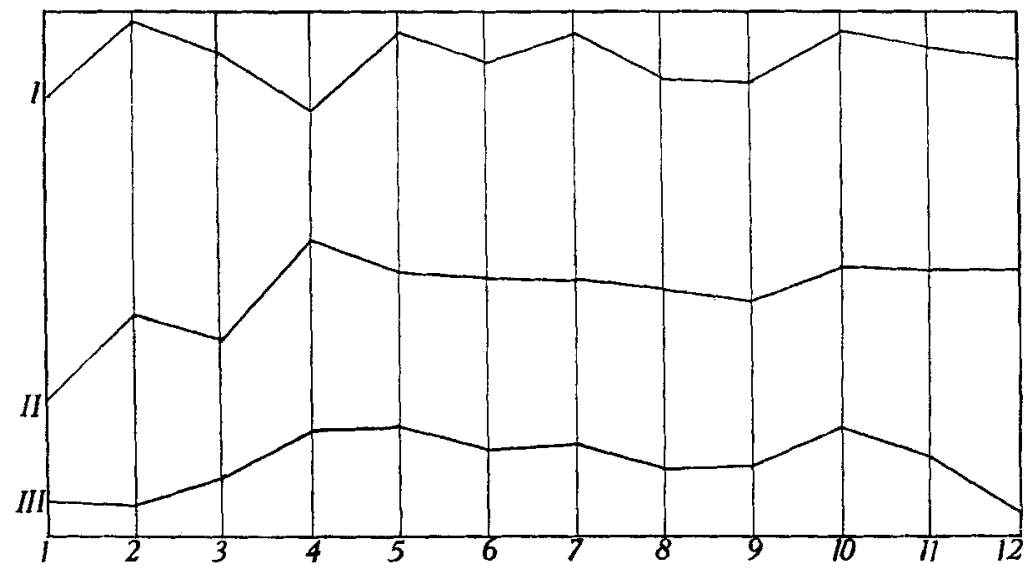

the largest nuclear diameter is during the early pupa stage with no marked variation in the average until the old adults are reached. The averages for these three types of cells seems to us to indicate that there is a definite series of growth sequences that follow through the life cycle in the worker bee and that they are not dependent on each other.

Beginning with the old adults taken at $6.30 \mathrm{a.m}$, there is a noticeable decrease in nuclear size in cells of Types I and III in the two following stages studied (11 and 12 of table) that is similar to Hodge's results. But there is a more marked decrease in nuclear size in Type I from mid-larva to early pupa. A similar change is indicated in the cells of Type II. If the change 
in nuclear size in old adults is due to fatigue or old age or both, how are we to explain the larval and pupal change? The larvae of the bee are inactive so that they are more like the pupa than is usual in insects. Metabolism is very active during the larval period but this can hardly result in fatigue to nuclei in the brain. One would expect that the changes that take place during the metamorphosis in the pupa would drain heavily on the energy of the insect, and yet the same rhythmic nuclear changes in size continue through this period. So far as activity is concerned these stages give us the two extremes, the larvae and pupae at rest, the adults of summer extremely busy and the winter workers relatively inactive. If there is a definite nuclear change with work, the stages selected should give us some indication of it. In place of definite nuclear change with age, we find a constant variation which tends to be rhythmic.

\section{CONCLUSIONS}

1. In the honey bee worker there is a definite variation in the nuclear size of the nerve cells studied.

2. Changes in nuclear size dependent on the life cycle are unlike in cells of different type.

3. The changes in nuclear size can not be explained as due to the effect of old age or fatigue. 